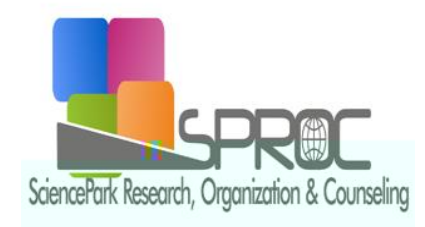

\section{Global Journal of Psychology Research: New Trends and Issues}

Volume 07 , Issue 1, (2017) 2-7
Global Journal of Psychology Research: New Trends and Issues

\title{
The association between vividness and verbal and figural creativity
}

www.gjpr.eu

Beatrice Adriana Balgiu*, Department of Social Sciences, University Politehnica of Bucharest, Splaiul Independenţei, 313, Bucharest, 060042, România

Victor Adîr, University Politehnica of Bucharest, Splaiul Independenţei, 313, Bucharest, 060042, România

\section{Suggested Citation:}

Balgiu, B.A. \& Adîr, V. (2017). The association between vividness and verbal and figural creativity.

$$
\text { . (1), 2-7. }
$$

Received October 15, 2016; revised January 5, 2017; accepted March, 17, 2017.

Selection and peer review under responsibility of Prof. Dr. Tulay Bozkurt, Istanbul Kultur University, Turkey. C2016 SciencePark Research, Organization \& Counseling. All rights reserved.

\section{Abstract}

Research on creativity in the technical field considers that one specific skill in the domain is spatial visualization,

. One of the essential characteristics of visualization with high value in creativity is vividness. Studies that took into consideration the implication of vividness in creativity show contradictory results. The present article analyses the vividness of visual imagery (using the Vividness of Visual Imagery Questionnaire - VVIQ) in verbal creativity (measured with "Unusual uses" test for creative thinking) and figural creativity (measured with Creative Mental Synthesis Tasks consisting in the mental assemblage of geometric figures). The correlational analysis shows a significant and positive, although moderate, connection between vividness and originality in creative mental synthesis tasks. There were no correlations between vividness and other parameters of verbal and figural creativity. Results make us believe that the role played by vividness in creativity is not as important as claimed by empirical studies or historical evidence provided by individuals who reported on the use of mental imagery in creativity.

Keywords: Vividness, mental imagery, verbal creativity, figural creativity.

\footnotetext{
* ADDRESS FOR CORRESPONDENCE: Beatrice Adriana Balgiu, Department of Social Sciences, University Politehnica of Bucharest, Splaiul Independenţei, 313, Bucharest, 060042, România
} : beatrice.balgiu@upb.ro / Tel.: +40-21-4029-271 


\section{Introduction}

The cognitivist approach of creativity proposes to make possible the understanding of processes that underlie creativity. One of the processes studied in creativity by cognitivism is the one of mental imagery, and in this context vividness stands out as a component of visual mental imagery (Gonzalez, Campos \& Perez, 1997; LeBoutillier \& Marks, 2003; Palmiero, Nakatani, Raver, Olivetti Belardinelli \& van Leeuwen, 2010; Palmiero, Cardi \& Olivetti Belardinelli, 2011; Vellera \& Gavard-Perret, 2016).

\section{The implication of the vividness of mental imagery in creativity}

The majority of studies which focused on the implication of mental imagery in creativity preponderantly used two essential variables of imagery: vividness and control. The results regarding the implication of these components and especially of vividness in the appearance of creativity are contradictory most of the times. For example, in the early studies, Forisha (1981) finds a consistent association between the control of mental imagery and divergent thinking, but not between vividness and divergent thinking. Parrot and Strongman (1985) report on opposite effects: thus, vividness is more strongly linked to creativity than to the control of mental imagery. In the meta-analysis of nine studies, Le Boutiller and Marks (2003) concluded that self-reported imagery is associated more with the figural aspect of creativity than with its verbal one. Similarly, Le Boutiller (1999 - Le Boutiller \& Marks (2003) discovered a significant relationship between vividness, mental imagery, and performance related to divergent thinking tasks. Theoretically, a person who shows a high degree of vividness and control of mental imagery is expected to obtain higher scores for figural tasks than for verbal tasks (Flowers \& Garbin, 1989). It seems that authors agree on the fact that visualisation interferes greatly with the figural side of creativity (Pearson, Logic \& Gilhooly, 1999; Antonietti \& Colombo, 2011). A special group of studies which focused on the role mental imagery plays in creativity is the one that used tasks of creative mental synthesis. In this context, Morrison and Wallace (2001) found a significant relationship between the vividness of visual imagery and the divergent production of tasks of creative mental synthesis, but not between the vividness of visual imagery, creativity, and the recognition of objects. Others authors discovered that there is no relationship between the vividness of visual imagery, originality, and the applicability of the objects generated during the tasks of mental synthesis (Palmiero, Nakatani, Raver, Olivetti Belardinelli \& van Leeuwen, 2010). In a subsequent study, Palmiero, Cardi and Olivetti Belardinelli (2011) discovered the positive relationship between vividness and the practicability of objects when concrete and functional drawings are solicited. The authors show that the objects evaluated as practical are associated with a high capacity to represent graphical information.

\section{Method}

Objective: the analysis of the implication of mental imagery vividness in creativity using two ways of measuring creativity

Participants: 64 students with the age range $M=20.11$ S.D. $=0.53$, out of which 43 were men, 23 were women with no significant difference regarding the age average.

\section{Measures}

- $\quad$ (Marks, 1973) used in order to measure the degree to which individuals can form visual mental imagery. The questionnaire presents 16 items which describe various scenes, for example

. The respective items were grouped in 
four scenes. After every scene, the subjects were asked to evaluate the degree of clarity in the visualisation of these scenes on a scale from 1 , to 5 -

(UNU) elaborated and standardized by Stoica-Constantin and Caluschi (2006) on a Romanian population in order to measure potential creative thinking $(\alpha=0,89)$. The test consists in discovering as many usages as possible for an ordinary cane with a spike at the lower end. The test lasts for 5 minutes. Creativity is summarized by its three dimensions, fluency (the total number of ideas), flexibility (the passage from one category of items to another) and originality (calculated by checking every answer against the list of items evaluated by means of a scale from 0 (banal) to 13 , where 13 is the minimum frequency of appearance, therefore, a high degree of originality. Finally, we add the originality scores for all the answers, thus, obtaining a score at this factor per test). The gross scores for the three dimensions are turned into a standard score on the progressive scale of 1 to 9 . Our prior experience with the respective test makes us believe that it is mainly based on the assessment of great creative force. Is considered that the test addresses the intellectual component of creativity and, at the same time, creative attitudes such as restructuring day-to-day life, focusing on risk, the sense of humour (the request to name less ordinary usages urges the subject to do away with common, stereotypical images).

(Finke, 1990) -

, consisting of the presentation of 15 tridimensional visual stimuli, with the corresponding names (sphere, semi-sphere, cube, cone, cylinder, rectangle, hook, thread, tube, bracket, square, cross, wheels, ring and handle) of which subjects had to make mental series of 3 stimuli in order to create a meaningful object. The presentation was made with a program made in Java Script which showed 8 series of 3 visual stimuli from the table of stimuli mentioned above. The respective stimuli were shown on the screen with the help of a computer and of a video projector. The participants were first familiarized with the shape and the names of every stimulus, and then asked to memorize the stimuli and, in the absence of the latter, to mentally assemble the three visual stimuli in order to create an object that should be a part of one of the three categories: toys, furniture, or weapons. Then, students had two minutes at their disposal to draw the objects they had mentally created, on papers given to them beforehand. The participants were allowed to change the size of the objects, the spatial orientation and the position of visual stimuli on the condition to keep the initial structure.

In order to evaluate the drawn objects, the consensual technique or the method of the judges was used (Amabile, 1983; Amabile, 2000). Two independent judges analysed and assessed the drawings taking into consideration the following dimensions:

, considered to be the ideational and figural rarity of the drawings. The drawings were assessed on a scale from 1 - low originality to 5 - high originality (interrater correlation $\alpha=.61$ ) defined as the adequacy to task constraints was assessed on a scale from 1 - low usefulness to 5 - high usefulness. The average of the two evaluators for each of the eight drawings was calculated, so that every participant received one score for originality and one for usefulness (interrater correlation $\alpha=.53$ ).

was calculated separately by using the rules recommended by Anderson and Helstrup (1993a; 1993b) and Palmiero, Cardi and Olivetti Belardinelli (2011). Every 
evaluator calculated 4 indexes for the sub-dimensions: size differences, rotation, image in the mirror and intrication.

The score for creativity subsumed all three dimensions: originality, usefulness, transformational complexity.

\section{Results and discussions}

Table 1 shows a descriptive statistics of the variables used in this study. With respect to originality and verbal creativity, the comparison of the results with the stanine sample test (nine classes) shows that the group is situated at a moderate level. With respect to figural creativity, the highest score was obtained for originality, while the lowest score was obtained for transformational complexity. Between originality and usefulness, the score difference is of $t=2,78 p=.005994$, and between originality and transformational complexity, the score difference is of $t=3,25, p=.005861$. There are no significant differences between the average value obtained for usefulness and that obtained for transformational complexity.

Table 1. Descriptive analysis

\begin{tabular}{llll}
\hline Measures & Variables & $\mathrm{M}$ & S.D. \\
\hline VVIQ & Vividness & 4,11 & 0,66 \\
& Fluency & 6,11 & 1,65 \\
\multirow{4}{*}{ CMST } & Flexibility & 6,50 & 1,62 \\
& Originality & 4,96 & 1,76 \\
& Creativity & 5.97 & 1,54 \\
& Originality & 14,95 & 3,59 \\
& Utility & 12,06 & 3,94 \\
& Transformational & 10,73 & 3,50 \\
& complexity & & \\
& Creativity & 12,25 & 1,54 \\
\hline
\end{tabular}

The drawings that obtained the highest scores for figural originality ( $M$ between 4 and 4,8) were considered the following: "table with a solar quadrant", "toy pirate arm", "rocket mini-launcher", "hairstyling chair", "chess bishop", "doll ring", "clown box", "electric drill" etc. For vividness, the average value was $M=4,11$, S.D. $=0,66$ (table 1 ). Table 2 shows the intervariables correlational analysis. Correlations between tests were obtained: between the variables that measure verbal creativity ( $r$ between 60 and 94; $p<0.01$ ) and within the internal structure that measures figural creativity ( $r$ between 32 and 90; $p<0.01$ ). There are no correlations between the two types of creativity measurements, the verbal and the figural one. Unlike the study carried out by Palmiero

(2011), the present research did not reveal any contribution of the dimension used in the creative process (equivalent with the predictability in the study of Palmiero (2011). The present results corroborate the researches that show a stronger relationship between vividness and figural creativity and the absence of the relationship between vividness and verbal creativity. The result suggests that the vividness of mental imagery is important for creativity because of the inspiration that figural imagery brings to subjects. 
Table 2. Intercorrelation of Variables

\begin{tabular}{|c|c|c|c|c|c|c|c|c|c|c|}
\hline Variables & & 1 & 2 & 3 & 4 & 5 & 6 & 7 & 8 & 9 \\
\hline \multirow{2}{*}{ VVIQ } & 1. Vividness & - & & & & & & & & \\
\hline & 2. Fluency & .17 & - & & & & & & & \\
\hline \multirow[t]{3}{*}{ UNU } & 3. Flexibility & .09 & $.90^{*}$ & - & & & & & & \\
\hline & 4. Originality & .03 & $.60^{*}$ & $.66^{*}$ & - & & & & & \\
\hline & 5. Creativity & .08 & $.94^{*}$ & $.93^{*}$ & $.79 *$ & - & & & & \\
\hline \multirow[t]{4}{*}{ CMST } & 6. Figural Originality & $.19 *$ & .15 & .11 & .00 & .19 & - & & & \\
\hline & 7. Utility & .09 & -.02 & -.07 & -.15 & -.04 & $.77 *$ & - & & \\
\hline & $\begin{array}{l}\text { 8.Transformational } \\
\text { complexity }\end{array}$ & -.18 & .03 & .05 & .07 & .07 & $.46^{*}$ & $.32 *$ & - & \\
\hline & 9. Figural Creativity & .06 & .06 & .01 & -.07 & .04 & $.90 *$ & $.87 *$ & $.66^{*}$ & - \\
\hline
\end{tabular}

**Correlation significant at the 0,01 level

\section{Conclusion}

Specialized literature has shown that mental imagery can play a role in the development of creativity. The present study investigated the relationship between vividness as a component of mental imagery and verbal and figural creativity. Results show that individual differences related to vividness influence creativity by means of the inspiration it brings to subjects. It follows then that the development of originality in solving figural tasks could be enhanced by enhancing visual imagery vividness, among other techniques. Moreover, the result suggests that it is important to select individuals who manage to have spatial visual representations with high intensity whenever one needs to solve creative tasks. Consequently, individual differences related to the vividness of mental imagery could have an important role when one proceeds to its enhancement.

\section{References}

Amabile, T. (1983).

Amabile, T. (2000).

, Boulder Co., Westview Press.

Anderson, R.E., \& Helstrup, T. (1993b). Visual discovery on mind and on paper, (3), 283-293

Anderson, R.E., \& Helstrup, T. (1993a). Multiple perspectives on discovery and creativity, In B. RoskosEwoldsen, M.J. Indos-Peterson \& R.E. Anderson (eds.)

(p. 223-253), Amsterdam, Elsevier

Antonietti, A., \& Colombo, B. (2011) Mental imagery as a strategy to enhance creativity in children,

Finke, R.A. (1990). (1), 63-77

Lawrence Erlbaum Associates

Flowers, J. H., \& Garbin, C. P. (1989). Creativity and perception, In J. A. Glover, R. R. Ronning, C. R. Reynolds (Eds.),

(p. 147-162).

New York, Plenum Press.

Forisha, B. L. (1981). Patterns of creativity and mental imagery in men and women,

$$
\text { , (1), 85-96. }
$$

Gonzalez, M. A., Campos, A., \& Perez, M. A. (1997). Mental imagery and creative thinking,

$$
\text { (4), 357-364. }
$$

LeBoutillier, N., \& Marks, D.F. (2003). Mental imagery and creativity: a meta-analytic review study, , (1), 29-44 
LeBoutillier, N. (1999). The role of mental imagery in creativity. Doctoral thesis. Middlesex University

Marks, F. (1973). Visual imagery differences in the recall of pictures, 17-24

Morrison, R.J., \& Wallace, B. (2001). Imagery, vividness, creativity and visual arts, $135-152$

Palmiero, M., Cardi, V., \& Olivetti Belardinelli, M., (2011), The role of vividness of visual mental imagery on different dimensions of creativity,

(4), 372-375

Palmiero, M., Nakatani, C., Raver, D., Olivetti Belardinelli, M., \& van Leeuwen, C., (2010), Abilities within and across visual and verbal domains: how specific is their influence on creativity?, , 369-377

Pearson, D.G., Logic, R.H., \& Gilhooly, K., (1999). Verbal representations and spatial manipulations during mental synthesis,

Stoica-Constantin, A., \& Caluschi, M. (2006). the Assessment of Creativity], laşi, Editura Performantica.

Vellera, C., \& Gavard-Perret, M. L., (2016), A better understanding of the role and underlying mechanism of stimulating mental imagery in improving the creativity of "ordinary" users, (English Edition), (3), 111-130. 